\title{
Spinal Epidural Abscess: When a Fast Diagnosis Is Necessary
}

\author{
Joana Cosme*, Joana Branco, Hermana Carneiro, Gheorghe Diviza, Carlos Chagas, \\ Emília Velhinho, Glória Silva \\ Serviço Medicina III, Hospital Pulido Valente, Centro Hospitalar Lisboa Norte, Lisboa, Portugal \\ Email: ${ }^{\text {joana.cosme@chln.min-saude.pt }}$
}

Received 15 November 2014; revised 10 December 2014; accepted 24 December 2014

Academic Editor: Jung Ho Park, Hallym University Sacred Heart Hospital, Republic of Korea

Copyright (C) 2014 by authors and Scientific Research Publishing Inc.

This work is licensed under the Creative Commons Attribution International License (CC BY).

http://creativecommons.org/licenses/by/4.0/

c) (i) Open Access

\section{Abstract}

A 61 years old man with fatty liver disease and history of recent urinary infection was admitted to the Department of Internal Medicine for severe back pain and fever. The blood culture exams were positive for methicillin-resistant Staphylococcus aureus and later the cervical spine MRI showed an anterior epidural abscess associated with medullary compression. The patient was kept under antibiotic therapy and a decompressive surgery was required. Spinal epidural abscess presentation can be subtle with its presenting complaints ranging in severity from nonspecific back pain to marked weakness. This case report highlights the importance of an early diagnosis in order to avoid a devastating outcome.

\section{Keywords}

\section{Spinal Epidural Abscess, Magnetic Resonance Imaging, Early Diagnosis}

\section{Introduction}

Spinal epidural abscess (SEA) is a rare pyogenic infectious disease with a potentially devastating outcome, located between the spinal dura mater and the vertebral periosteum [1] [2].

It was first described by Morgagni in 1761 but it was clearly defined only in 1820 by Bergamaschi [2].

The prevalence of this condition has increased in the last decades [1] [2] from $0.2-1.2$ cases per 10,000 hospital admissions in the mid-1970s to a current estimated incidence of 2 - 12.5 per 10,000 admissions [2]. Population aging, increased prevalence of injection drug use, of spinal instrumentation and of vascular access, as well

${ }^{*}$ Corresponding author.

How to cite this paper: Cosme, J., Branco, J., Carneiro, H., Diviza, G., Chagas, C., Velhinho, E. and Silva, G. (2014) Spinal Epidural Abscess: When a Fast Diagnosis Is Necessary. Case Reports in Clinical Medicine, 3, 664-668.

http://dx.doi.org/10.4236/crcm.2014.312140 
as, greater availability of magnetic resonance imaging (MRI) and greater awareness of SEA are probably the main responsible for this increase [2]. It occurs in patients from 10 days to 87 years, with most cases occurring in those 30 - 60 years old [1]. The increasing patient age has been shown to be a poorer prognostic factor [1].

Staphylococcus aureus is the most common pathogen involved in this infection, responsible for approximately two-thirds of spinal abscesses [1]-[3]. Other pathogens including gram-positive and gram-negative bacteria, anaerobic bacteria, mycobacteria, fungi, and parasites have also been implicated [3]. The most common abscess location is the lumbar spine (48\%), followed by the thoracic spine (31\%) and then the cervical spine (24\%) [2].

The treatment of SEA is two-pronged: medical with antibiotics and surgical with laminectomy [3].

Despite being a rare condition SEA is associated with high mortality rate, ranging from $15 \%$ to $23 \%$ [1].

As SEA has a wide variation of causes, clinical presentation and locations. A high level of alert and suspicion are essential for an accurate diagnosis. In this article, we empathize the importance of a fast diagnosis in avoiding a devastating outcome.

\section{Case Report}

A 61 years old man, caucasian, farmer with arterial hypertension and dyslipidemia and with history of acute myocardial infarction three years before, was admitted to the Department of Internal Medicine in Hospital Pulido Valente in North Lisbon Hospital Center. His daily medications were hydrochlorothiazide/olmesartan, carvedilol, pitavastatin, acetilsalicilic acid, clopidogrel, omeprazol, bromazepam and naproxen. He referred alcohol consumption (approximately 35 grams of alcohol per day) and fatty liver history.

His symptoms at admission were back severe pain with 5 days of evolution and fever (maximum axillary temperature measured of $38.5^{\circ} \mathrm{C}$ ). Five days prior to admission it was prescribed amoxicillin/clavulanic acid for an urinary infection. There was no history of previous spinal trauma or surgery, drug usage or other invasive exams besides coronarography with angioplasty 3 years before.

The physical examination revealed redness on his back. Body temperature and others vital parameters were stable at admission. Neurological examination revealed sensory motor quadriparesis. Power was grade 2 in the lower limbs and grades 1 in the upper limbs.

Laboratory analyses revealed the following: White blood cell count: $10.59 \times 10^{9}$ cells/L with differential count: neutrophils, $64 \%$; lymphocytes $25 \%$; monocytes $9 \%$; eosinophils $1 \%$; basophils $1 \%$; red blood cell count $5.34 \times$ $10^{12}$ cells/L; haemoglobin $15.0 \mathrm{~g} / \mathrm{L}$; platelets, $163 \times 10^{9}$ platelets/L; alanine aminotransferase $90 \mathrm{U} / \mathrm{L}$; C-reactive protein $3.4 \mathrm{mg} / \mathrm{dL}$, creatinine $0.9 \mathrm{mg} / \mathrm{dL}$. The patient was HIV negative. All viral serologies were negative.

The cervical radiography showed a loss/straightening of cervical lordosis (Figure 1) and the cervical and lumber computerized tomography scan did not showed other aspects besides this.

The urine culture was negative and all the blood culture exams (two in aerobiosis and one in anaerobiosis) were positive for methicillin resistant Staphylococcus aureus. The patient was immediately treated with vancomycin and further imaging was performed with cervical spine MRI that showed anterior epidural abscess extending from C2 to C6 vertebral bodies low signal intensity on T1-weighted images, and high signal intensity on T2-weighted images and STIR and with gadolinium enhancement, associated with medullary compression (Figure 2 and Figure 3). The serial levels of vancomycin where monitorized.

These findings as well as the persistent and worsening back pain associated with a sudden onset of flaccid tetraparesis led to the decision to urgently transfer the patient for specialised surgical intervention.

The patient underwent spinal decompression. After the surgery the patient continued the antibiotic therapy and physical rehabilitation for more than a month. After surgery, repeated spinal imaging exams and neurological examinations were made. There was a progressive resolution of the pain and a partial recovery of the limbs strength (power improved for 3 - 4) and of the ability for walking. After clinical and analytic stability he was transferred to a physiatrist unit to continue his neurologic recovery. The patient will continue his follow up evaluations in neurosurgery and infectious diseases units.

\section{Discussion}

Despite the advances in its medical and surgical treatment, SEA remains a morbid disease process.

The learning point from this case is the need for early diagnosis and urgent intervention. A complete history and clinical examination and a high level of suspicion are essential in the diagnosis of this condition.

In this case reports there are, however, three other key points that must be highlighted. The first is that 


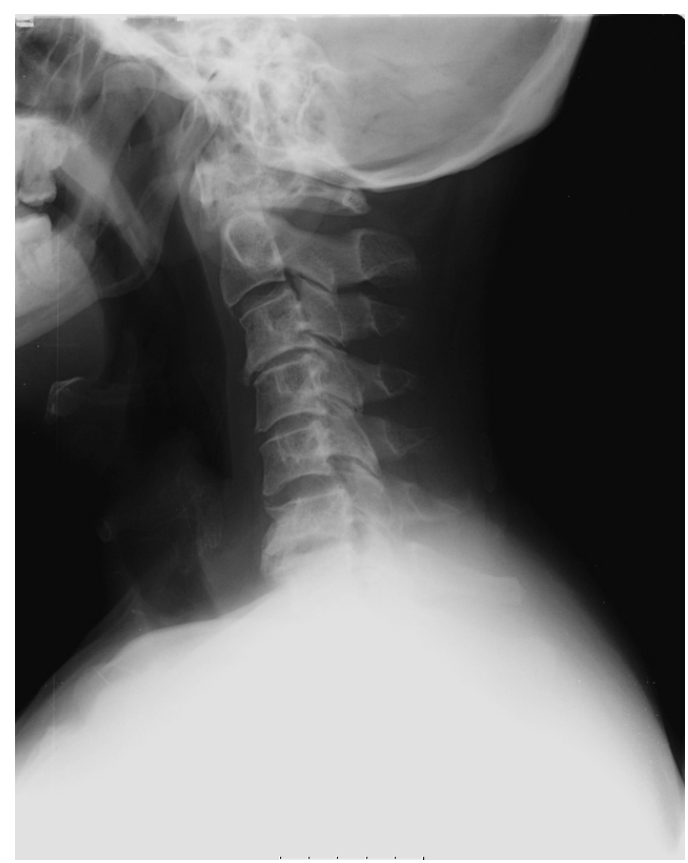

Figure 1. Patient cervical radiography.

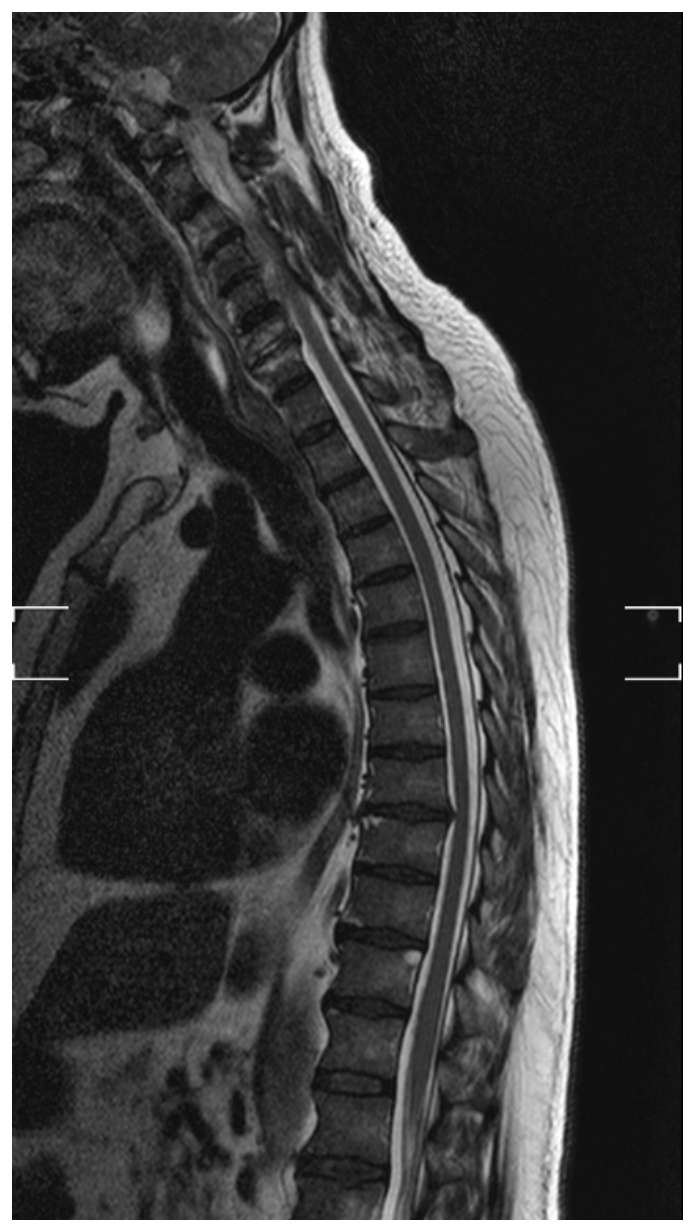

Figure 2. Patient cervical spine magnetic resonance imaging. 


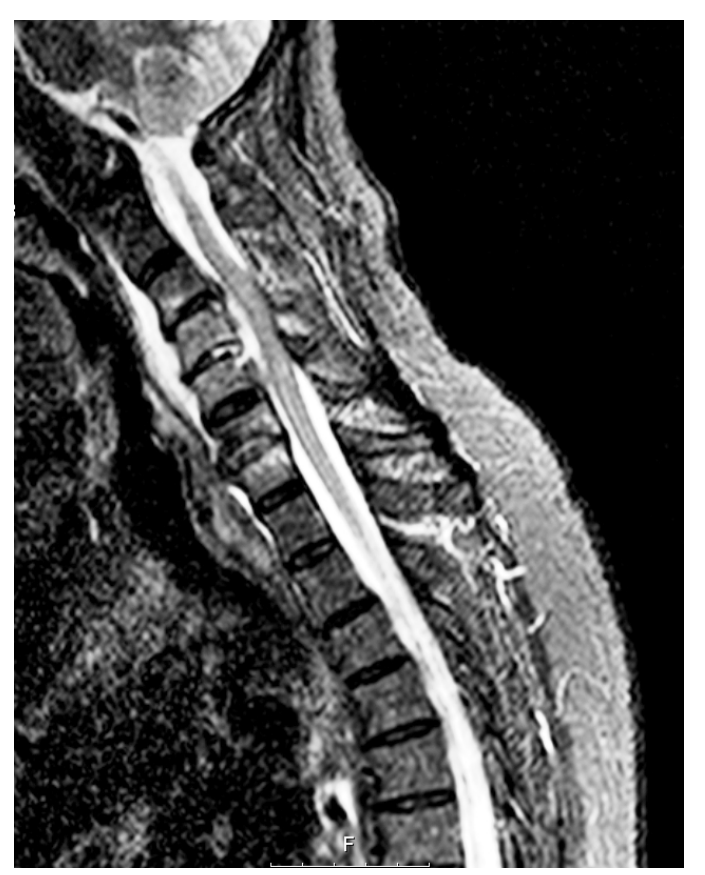

Figure 3. Patient cervical spine magnetic resonance imaging.

although the pain associated with a spinal abscess typically becomes severe and unrelenting, the presentation of this condition can be subtle and insidious. It is import to be aware that patients' presenting complaints rang in severity from nonspecific back pain to marked weakness [1].

Secondly, there are several risk factors and medical comorbidities associated with the development of SEA. L. Arko et al. (2014) showed that intravenous drug use was the most frequently reported risk factor (22\% of patients with SEA) and diabetes (27\%) and hepatic disease (14\%) the most common medical comorbidities [2]. O. Adogwa et al. (2014) pointed out other risk factors: diabetes mellitus (38\%), end-stage renal disease (24\%), history of endocarditis (9\%), recent history of urosepsis (6\%), rheumatoid arthritis (5\%) and history of spinal trauma (2.4\%) [1]. According to S. Zimmerer et al. (2011) the risk of SEA is higher in immunocompromised person (e.g. persons who have the acquired immune deficiency syndrome or are under immunosuppressive treatment after organ transplantation) or in patients with history of drug addiction, alcoholism, cancer, and systemic inflammation or infection [4]. Despite this, SEA can also occur in the absence of predisposing factors. Verma $\mathrm{R}$ et al. (2014) described a case of a 35-year-old-man with an extensive SEA that, like the patient described above, had no risk factors commonly associated with the development of SEA. These authors labelled this condition as "spontaneous SEA" [5].

Thirdly, although the changes on the initial cervical spine radiograph and spine computerized tomography are subtle and did not point to a specific diagnosis, MRI is essential for the establishment of the diagnosis.

The patients' prognosis in this type of condition is dependent not only on the clinical and neurological condition of the patient at presentation but also on the timing for instigation of an appropriate treatment [6]. For this reason, in a neurosurgical emergency like this, a prompt diagnosis and urgent treatment are essential to a successful management and to avoid high rates of morbidity and mortality [5] [6].

\section{Conclusions}

SEA is a rare event with significant variation in its causes, anatomical locations and rate of progression.

A highest degree of suspicion and appropriate investigations and treatment without delay are essential to reduce the morbidity and mortality associated with this condition. MRI is essential to an early diagnosis.

\section{References}

[1] Adogwa, O., Karikari, I., Carr, K., Krucoff, M., Ajay, D., Fatemi, P., Perez, E., Cheng, J., Bagley, C. and Isaacs, R. 
(2014) Spontaneous Spinal Epidural Abscess in Patients 50 Years of Age and Older: A 15-Year Institutional Perspective and Review of the Literature. Journal of Neurosurgery: Spine, 20, 344-349. http://dx.doi.org/10.3171/2013.11.SPINE13527

[2] Arko, L., Quach, E., Nguyen, V., Chang, D., Sukul, V. and Kim, B.S. (2014) Medical and Surgical Management of Spinal Epidural Abscess: A Systematic Review. Neurosurgical Focus, 37, E4. http://thejns.org/doi/pdf/10.3171/2014.6.FOCUS14127

[3] Tuchman, A., Pham, M. and Hsieh, P.C. (2014) The Indications and Timing for Operative Management of Spinal Epidural Abscess: Literature Review and Treatment Algorithm. Neurosurgical Focus, 37, E8. http://dx.doi.org/10.3171/2014.6.FOCUS14261

[4] Zimmerer, S., Conen, A., Muller, A., Sailer, M., Taub, E., Fluckiger, U. and Schwenzer-Zimmerer, K. (2011) Spinal Epidural Abscess: Aetiology, Predisponent Factors and Clinical Outcomes in a 4-Year Prospective Study. European Spine Journal, 20, 2228-2234.

http://www.ncbi.nlm.nih.gov/pmc/articles/PMC3229722/pdf/586_2011_Article_1838.pdf http://dx.doi.org/10.1007/s00586-011-1838-y

[5] Verma, R., Chaudhari, T.S. and Lachuriya, G. (2014) Spontaneous Extensive Spinal Epidural Abscess Presenting as Acute Quadriparesis. BMJ Case Reports. http://casereports.bmj.com/content/2014/bcr-2014-204892.full.pdf+html

[6] Mackenzie, A., Laing, R.B.S., Smith, C.C., Kaar, G.F. and Smith, F.W. (1998) Spinal Epidural Abscess: The Importance of Early Diagnosis and Treatment. Journal of Neurology, Neurosurgery \& Psychiatry, 65, 209-212. http://europepmc.org/backend/ptpmcrender.fcgi?accid=PMC2170211\&blobtype=pdf http://dx.doi.org/10.1136/jnnp.65.2.209 
Scientific Research Publishing (SCIRP) is one of the largest Open Access journal publishers. It is currently publishing more than 200 open access, online, peer-reviewed journals covering a wide range of academic disciplines. SCIRP serves the worldwide academic communities and contributes to the progress and application of science with its publication.

Other selected journals from SCIRP are listed as below. Submit your manuscript to us via either submit@scirp.org or Online Submission Portal.
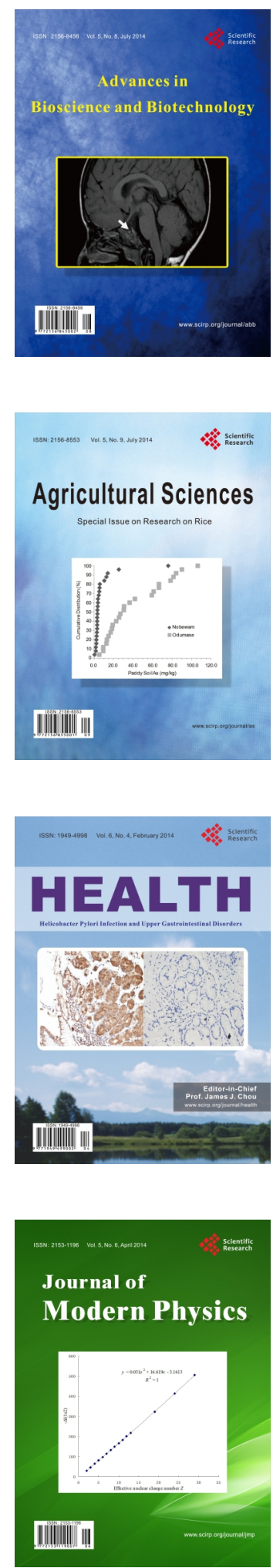
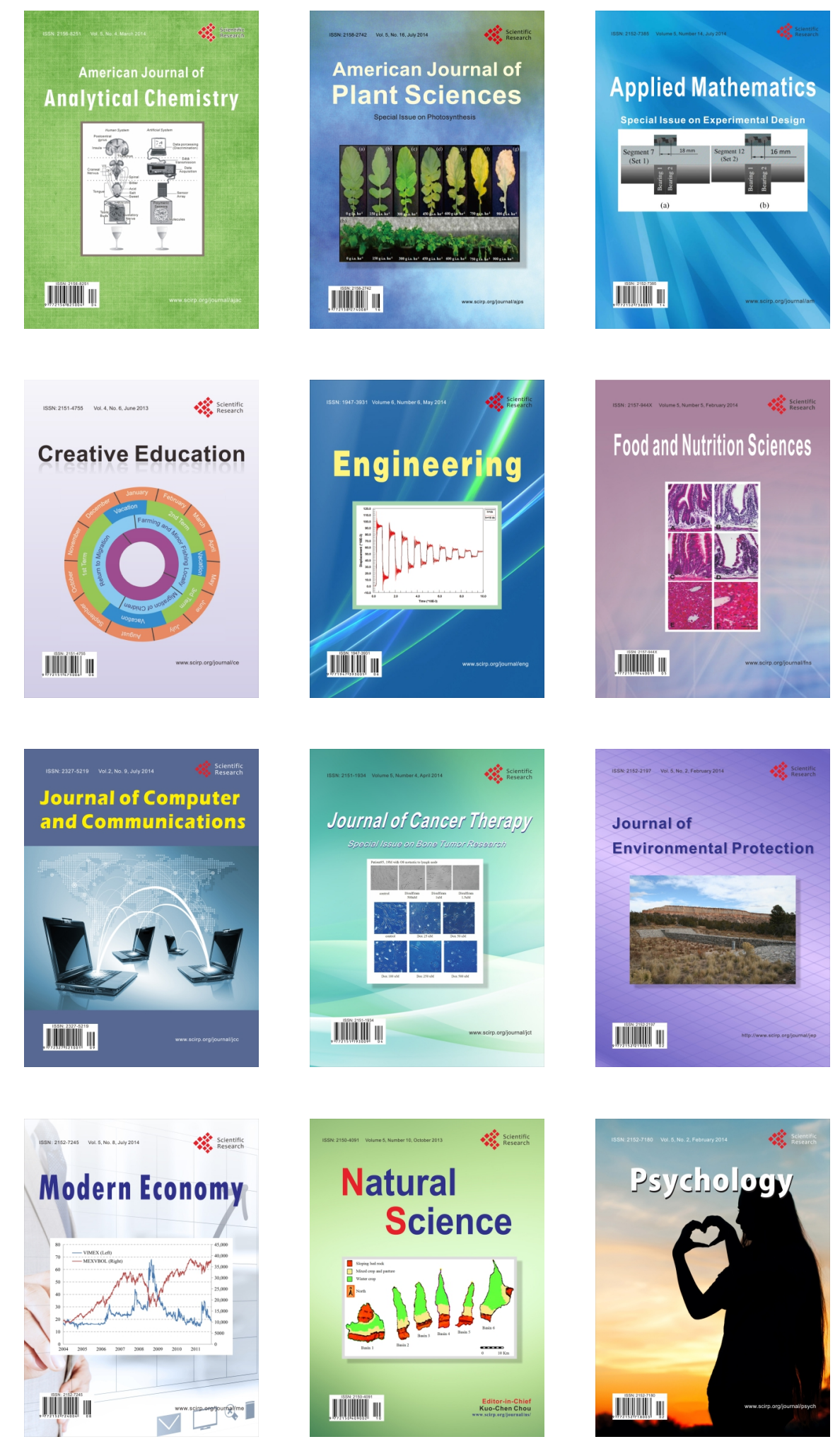